\title{
Assessing the Impact of Operational Constraints on the Near-Term Unmanned Aircraft System Traffic Management Supported Market
}

\author{
Parker D. Vascik ${ }^{1}$ \\ Massachusetts Institute of Technology, Cambridge, Massachusetts, 02139 \\ Jaewoo Jung ${ }^{2}$ \\ National Aeronautics and Space Administration, Moffett Field, California, 94035
}

\begin{abstract}
An economic impact market analysis was conducted for 16 leading sectors of commercial Unmanned Aircraft System (UAS) applications that are expected to be supported in the near-future with the findings from the NASA UAS Traffic Management (UTM) project. Subject matter experts from industries were interviewed to validate concept of operations and market adoption assumptions for each sector. The market analysis was used to estimate direct economic impacts for each sector including serviceable addressable market, capital investment, revenue recovery potential, and operations cost savings. The resultant economic picture distinguishes the agricultural, pipeline and railroad inspection, construction, and maritime sectors of the nascent commercial UAS industry as providing the highest potential economic value in the United States. Sensitivity studies characterized the variability of select UAS sectors' economic value to key operational constraints such as weight, altitude, and flight over populated area. This work concluded in August 2015 and reflects the state of the UAS industry and market projections at that time.
\end{abstract}

\section{Introduction}

$\mathrm{T}$ HE Unmanned Aircraft System (UAS) industry is currently on the verge of rapid technological development and market expansion. Significant military investment in UAS technologies began in the late 1980's and accounted for a majority of worldwide UAS development for the past three decades; investments by the US Department of Defense alone accounted for nearly \$30 billion between 1988 and 2013. ${ }^{1}$ Although military investments continue to dwarf the commercial UAS sector, commercial UAS platform development and sales have expanded dramatically in the past five years. ${ }^{2}$

Commercial UAS are fundamentally different from their military counterparts, which have been typically developed by a small set of established contractors. Market entry by new companies is limited in the military sectors due to the extensive technical expertise, capital investment, and security assurances that are necessary to garner contract awards. The commercial UAS industry is changing this paradigm. In particular, commercial small UAS (sUAS) development, or vehicles defined by the Federal Aviation Administration (FAA) Modernization and Reform Act (FMRA) of 2012 as unmanned aircraft weighing under 55 pounds ${ }^{3}$, presents fewer barriers to market entry for new companies than the traditional military UAS sector. This is in part due to the low development and production costs of sUAS. ${ }^{4}$ Furthermore, a substantial multi-buyer market encompassing dozens of industries exists for commercial sUAS. ${ }^{5}$ Due to these differences, the sUAS industry is emerging as a highly competitive sector supporting numerous start-up service providers, manufacturers and technology developers. ${ }^{6}$ Incumbent aerospace prime contractors such as Boeing and Northrop Grumman find themselves sharing the sUAS market with new manufacturers such as DJI or 3D Robotics, out of sector developers such as Facebook or Amazon, and small start-up companies designing niche market vehicles. ${ }^{2}$

Despite the significant investment and entrepreneurial activity of the current sUAS industry, commercial UAS operations in the United States are rather limited, enabled only by acquiring a FMRA Section 333 exemption with a certificate of waiver or authorization, or a special airworthiness certificate. However, it is widely proposed that pending the adaptation of local laws and FAA regulations to address the challenges of UAS operations in the

${ }^{1}$ Graduate Research Assistant, SEAri, MIT, 77 Massachusetts Avenue, E38-554, Student Member, AIAA.

${ }^{2}$ Aerospace Engineer, NASA Ames Research Center, Moffett Field, Senior Member, AIAA.

1

American Institute of Aeronautics and Astronautics 
National Air Space (NAS), the commercial market will drive the rapid diversification of UAS technologies and missions to serve new market sectors in the United States and abroad. ${ }^{7}$ For example, numerous commercial UAS and sUAS applications have been proposed, with a wide range of vehicles and concept of operations (ConOps) such as lighter than air dirigibles inspecting photovoltaic arrays ${ }^{8}$, multi-hundred pound helicopters applying pesticides to farms $^{9}$, infrastructure inspection and monitoring with multi-rotor and fixed-wing sUAS ${ }^{10}$, and aerial package delivery with UAS. ${ }^{11}$

In light of the anticipated increase in commercial UAS flights, in particular sUAS operations at low altitudes in airspace not currently managed by the FAA, NASA developed the UAS Traffic Management (UTM) project to research prototype technologies, such as dynamic geo-fencing and congestion management, to "enable safe, efficient low-altitude operations." ${ }^{12}$ The UTM prototype also applies a set of operational constraints, such as a maximum altitude flight ceiling and visual line of sight requirement, in traffic management.

Previous works on UAS market value have been conducted without consideration of a traffic management perspective. This paper estimates the value of commercial sUAS markets supported by the UTM prototype technologies in the near future, and assesses the impact of operational constraints on the market value.

This paper is organized as follows. Section II describes methods used to classify commercial sUAS market sectors that could be supported by the UTM by year 2020, and presents metrics to quantify market value of each sector. Section III discusses sensitivity of the market value to changes in the operational constraints. Section IV concludes the paper with a summary of key findings.

\section{Analysis Methods}

\section{A. Commercial UAS Application Identification and Classification}

The first step of the analysis involved characterizing the commercial UAS industry as broadly as possible by identifying the range of proposed vehicles and missions. Vehicle type, performance and cost data were collected for about 400 vehicles by examining UAS literature and manufacturer provided information. Additionally, 135 unique representative UAS applications were identified that, while not a complete listing, provided a representative sampling of the UAS applications landscape.

The ConOps for each of the 135 applications was roughly defined, and applications with similar mission architectures and technologies were grouped into broad mission categories. This process resulted in the definition of five fundamental UAS mission categories that represent the basic ConOps of currently proposed commercial UAS activities. The five UAS mission categories proposed below more succinctly capture the anticipated commercial market operations than a 10 mission category classification introduced by Ref. 13 and adopted by Ref. 5 .

1) Aerial Photography, Sensing and Surveillance: Aerial photography, sensing and surveillance missions span from property patrol to infrastructure management to real estate appraisal. UAS executing these missions collect imagery and data with a variety of electromagnetic or acoustic sensors and equipment.

2) Communications: UAS are proposed to serve as strategic communications relays for underserved regions. While a majority of these vehicles will be large, high altitude, long endurance UAS and are beyond the current scope of UTM, this mission type may find some applications with small vehicles at low altitudes in dynamically congested or highly remote areas, such as for rapidly configurable search and rescue communication or cellular networks.

3) Transportation, Delivery and Interaction: The capacity of a UAS to potentially transport and deliver goods and services is highly anticipated. Aerial crop dusting within Visual Line of Sight (VLOS) by UAS has been a reality in Japan for over two decades, and the aerial delivery of products is a major anticipated development. Missions of this type have been met with a large degree of public attention due to the involvement and development efforts of large companies such as Amazon, Google and FedEx. This mission type also presents promise to more cost effectively move goods in areas with seasonally available or unavailable ground transportation infrastructure, such as in Alaska.

4) Atmospheric and Earth Science: UAS provide unique capabilities to conduct air quality testing, weather exploration and other atmospheric science missions at low cost. Although similar to mission category 1 , these missions often require specialized equipment and direct interaction of the UAS with the phenomenon under study.

5) Audiovisual Presence: UAS may have marketable applications that simply rely upon their physical presence, perhaps enhanced through visual and acoustic means. These include aerial advertising, tour guiding, or visual indication for search and rescue. 
The Appendix contains a table displaying the 135 applications organized by the fundamental UAS mission category of their ConOps. Since the UTM prototype consists of four Technology Capability Levels (TCLs) of increasing complexity, these applications are further identified with requisite enabling UTM TCL level through color-coding. Following is an excerpt from Ref. 12, describing TCLs 1 to 4.

UTM TCL 1: Concluded field testing in August 2015/ongoing testing at FAA site. Addressed rural UAS operations for agriculture, firefighting and infrastructure monitoring. In this TCL, the UAS ground pilot reserved the airspace and adjusted the flight plan if notified of a conflict.

UTM TCL 2: Tests in October 2016 to address beyond-visual line-of-sight operations in sparsely populated areas, and provide flight procedures and traffic rules for longer-range applications.

UTM TCL 3: Tests in January 2018 to include cooperative and uncooperative UAS tracking capabilities to ensure collective safety of manned and unmanned operations over moderately populated areas.

UTM TCL 4: Test dates to be determined. Would involve UAS operations in higher-density urban areas for tasks such as news gathering and package delivery, and large-scale contingency mitigation.

\section{B. 2020 Leading Applications Down-Selection}

This step of the market analysis identified the commercial sUAS applications that are likely to achieve moderate to large market penetration by 2020. UTM TCL 1 and 2 flight demonstrations are expected to occur in the fall months of 2015 and 2016, respectively. UTM TCL 3 is expected in January 2018 and TCL 4 dates are to be determined. Based upon these dates, and considering the time between the demonstration, transfer of results to the FAA, and the resultant introduction of new UAS operations in the industry, an assumption was made for this study that only UAS applications supported by the results of UTM TCLs 1 and 2 would be implemented on sufficient scale in the market by 2020 to warrant investigation at this time.

Under this assumption, 74 commercial applications were identified from the initial list of 135 to be enabled by UTM TCLs 1 or 2 . From a review of these 74 potential applications, 16 representational market sectors were selected to form the economic impact market analysis. The down-selection of the applications from 74 to 16 was necessary to remove small, economically inconsequential applications (such as archeology mapping), combine applications with similar ConOps (maritime scouting and maritime search and rescue), and best utilize the limited study resources on the most significant market sectors. Each sector was developed with the following traits:

- $\quad$ The sector represented one or more sUAS applications enabled by UTM TCLs 1 or 2

- $\quad$ The sector represented a substantial market penetration potential by 2020

- The sector had the potential for significant economic impact, or the potential to provide a valuable ancillary benefit such as the protection of life and property

Table I on the next page presents the 16 market sectors considered by this economic impact market analysis and provides a brief description of each. Each of these sectors will be defined and reviewed in depth through the remainder of this analysis. It should be noted that some sectors, such as dam and bridge inspection, represent a joint civil and public (government) UAS market. For these sectors, the market analysis shall be completed under the assumption that the public entities contract UAS services from commercial companies. Under this assumption the economic value of such sectors is captured in the civil market rather than the public market.

\section{Sector Economic Impact Market Analysis Methodology}

An economic impact market analysis was completed for each of the 16 commercial sUAS sectors identified. While the exact approach for the market analysis varied depending upon unique factors of each sector, the general approach is outlined in Figure 2. The approach is best described as an iterative data collection process to develop three modules for each sector: the sector ConOps, the sector market size, and the general business case for a provider operating a sUAS business in that sector. Three types of data sources were utilized to collect information and validate assumptions: subject matter expert (SME) interviews, primary source data collection, and multi-source estimation from secondary sources. The final steps of the market analysis involved selecting a representative sUAS vehicle to meet the needs of the specific ConOps and business case. Once a representative vehicle had been selected, the economic impact of the sUAS sector was estimated along a variety of market metrics. Each of the steps in this methodology is described in detail through this section. 
Table I. Projected 2020 leading commercial sUAS market sectors. Through a review of 135 proposed sUAS applications, sixteen market sectors were identified where market entry depends upon technologies and ConOps testing that is anticipated to be completed through NASA UTM by 2020.

\begin{tabular}{|c|c|c|}
\hline & Market Sector & Description \\
\hline \multirow{3}{*}{ 葛 } & $\begin{array}{l}\text { Cropland Precision } \\
\text { Agriculture }\end{array}$ & $\begin{array}{l}\text { Inspection of crops, pasture and property through the use of a variety of } \\
\text { imaging sensors }\end{array}$ \\
\hline & $\begin{array}{l}\text { Pasture/Range } \\
\text { Management }\end{array}$ & $\begin{array}{l}\text { Activities such as herd counting, pasture inspection, sick/injured animal } \\
\text { identification, birth detection and containment inspection, among others }\end{array}$ \\
\hline & Aerial Application & The spreading of chemicals, water, or other substances on crops \\
\hline \multirow{5}{*}{ 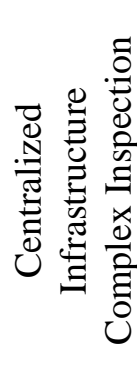 } & Wind Turbine Inspection & Turbine blade and superstructure visual inspections \\
\hline & Solar Array Inspection & Visual and infrared inspection of photovoltaic (PV) solar arrays \\
\hline & Dam Inspection & $\begin{array}{l}\text { Visual inspection of potential hazardous areas such as dam face, } \\
\text { spillway, abutments, reservoir, and other structures }\end{array}$ \\
\hline & $\begin{array}{l}\text { Heavy Industry } \\
\text { Inspection }\end{array}$ & $\begin{array}{l}\text { Infrastructure inspection in power plants, oil rigs, petroleum refineries, } \\
\text { petrochemical plants, steel mills, pulp and paper mills, cement facilities } \\
\text { and coal processing plants }\end{array}$ \\
\hline & $\begin{array}{l}\text { Communications Tower } \\
\text { Inspection }\end{array}$ & At height inspection of cell, microwave, radio and television towers \\
\hline \multirow{5}{*}{ 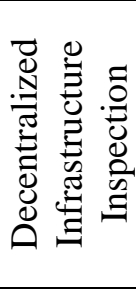 } & Pipeline Inspection & Airborne inspection of difficult or $\mathrm{d}$ \\
\hline & Power Line Inspection & $\begin{array}{l}\text { Pylon and at-height wire inspection of transmission lines as well as } \\
\text { right of way intrusion monitoring }\end{array}$ \\
\hline & Railroad Inspection & Visual inspection of railroad tracks \\
\hline & Bridge Inspection & At-height inspection of bridge superstructure and substruc \\
\hline & $\begin{array}{l}\text { Railroad Trestle } \\
\text { Inspection }\end{array}$ & At-height inspection of trestle superstructure and substructure \\
\hline \multirow{3}{*}{ 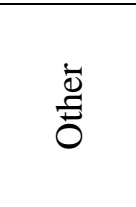 } & Search and Rescue & Airborne communications, detection and equipment transport assets \\
\hline & $\begin{array}{l}\text { Maritime Security and } \\
\text { Surveillance }\end{array}$ & $\begin{array}{l}\text { Assets for anti-piracy, weather monitoring, hull inspection, channel } \\
\text { navigation, fish spotting and route mapping, among others }\end{array}$ \\
\hline & Construction & $\begin{array}{l}\text { Airborne Surveying, safety and quality inspection, and documenting of } \\
\text { build progress }\end{array}$ \\
\hline
\end{tabular}

\section{Sector ConOps Definition}

A thorough understanding of the ConOps for each application in a sector is essential to characterize the airspace and technology needs required for UTM. Care was taken to identify how the application was previously achieved (use of manned aircraft, ground vehicles, climbers, not conducted, etc.). The vehicle requirements were defined through parameters such as speed, operating altitude, endurance, range and payload. Finally, the airspace required by the ConOps was defined through metrics such as the underlying population density, UAS and manned aircraft operations density, and altitude ceilings.

\section{Sector Size Characterization}

The second step of the market analysis was to determine the size of the sector. The sector size was evaluated in this research using the number of single operator service providers the sector could support as a proxy. The process of determining this characteristic varied widely from sector to sector, however the basic approach involved determining the total sUAS service opportunity (number of missions demanded), applying market adoption (penetration) estimates, and then dividing the remaining service opportunity by the projected

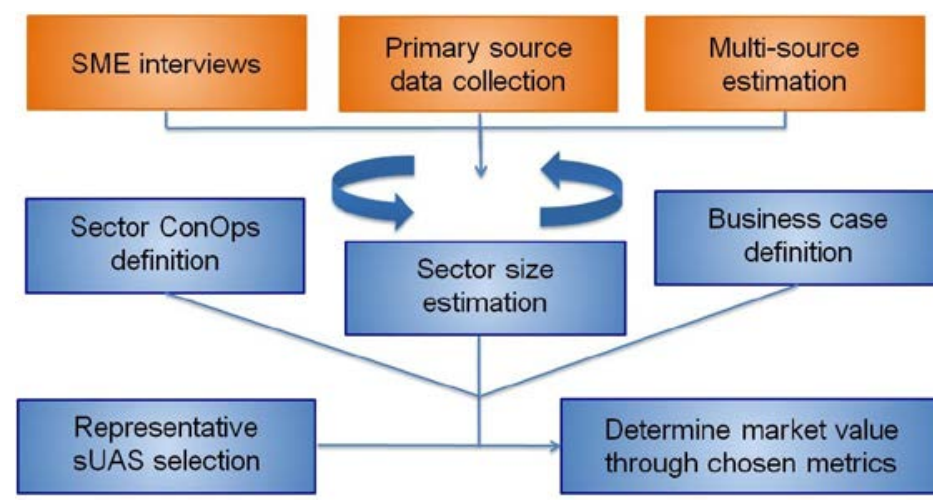

Figure 2. UTM economic impact market analysis approach. The economic impact of each market sector resulted from the characterization of proposed or existing business operations in the sector, and an understanding of their potential 2020 market penetration. 
capabilities of a single operator service provider (operating a single vehicle at a time). This method resulted in defining the total number of operators the market sector could feasibly support.

For example, the total sUAS service opportunity for power line inspection may be represented by the mileage of power lines inspected annually in the country (forecasted to 2020). This total sUAS service opportunity for power line inspection may be reduced by market adoption assumptions: only transmission lines will be inspected by sUAS (excludes distribution lines), and only transmission lines located in rural areas will be inspected (excludes lines in suburban and urban areas). The market adoption rate, typically estimated by a SME, is then applied and represents the percent of the service potential that is projected to be fulfilled by sUAS service providers in 2020. Three different adoption estimations were evaluated in this analysis due to the uncertain nature of this estimate: base, medium and high market adoption. Finally, the capabilities of a single operator service provider are based upon the operational capabilities of the representative sUAS chosen for the sector and, where available, interviews with current service providers in the market.

This process for defining sector size is dependent upon a few key assumptions central to this analysis. First of all, it should be reiterated that the sector size characterization typically assumes that all sUAS services are provided by an independent, single operator service provider. This assumption suggests that a farmer or oil company hires a service provider to complete their sUAS mission rather than purchasing their own sUAS to internally meet the need. While this assumption does not accurately represent the mix of service models that will exist in the actual market, it is useful to assess the total value of the industry, albeit not the distribution of who captures this value.

The independent sUAS service provider model provides an accurate assessment of the total value of the market opportunity. However, the model likely underestimates the number of operators and vehicles that will actually exist because the model promotes an implicit assumption of $100 \%$ efficiency of sUAS service delivery. Actual service delivery efficiency is limited by logistics, non-uniform service demand, and other market factors. Finally, a service provider is assumed in this analysis to consist of a single sUAS operating outfit (pilot, observer, other necessary personnel for the mission) using a single vehicle. This assumption is intended to represent the current regulations that require pilot-in-the-loop flight and prohibits multiple UAS operating under one pilot. The metric is therefore useful to capture total employment potential for the sector. However, the single vehicle per service provider assumption likely overestimates the number of companies that would exist to meet the sector need a business will likely employ more than one pilot and sUAS system. Changes in future regulations may also allow a single pilot to operate multiple vehicles simultaneously.

As a result of the limitations of the independent sUAS service provider model outline above, a second service model was also explored. For some industries an internal service provider model was assumed where a client invests in in-house sUAS operating capabilities and assets. This assumption was applied to sectors such as maritime security and surveillance where an independent service provider model was unlikely to meet the mission needs. The use of an internal service provider model likely results in an overestimation of the number of sUAS in operation and an underestimation of the market value. The actual split between an internal or independent sUAS service model will depend heavily upon the cost of UAS insurance, the cost of the vehicles, and the regulatory requirements for pilot certification.

\section{Sector Business Case Definition}

The third step of the market analysis was to outline the business case for a hypothetical sUAS operator in the sector. The purpose of this process is to understand the financial operating characteristics of the sUAS application and project the total sector value metrics, based on the number of service providers previously estimated in the sector size characterization. SME engagement, financial records, market studies, operator service fees, and news articles were utilized to estimate a variety of cost information including sUAS service fees, current manned mission costs, estimated efficiency improvements, production downtime reduction and safety improvement value, among others. Where necessary, differences between sUAS operations costs and status quo operations costs were elicited for both an internal provider model and an independent service provider model.

It should be noted that all financial figures in this analysis are presented in 2015 equivalent dollars. Additionally, it was assumed that except in the case of bridge, dam, and trestle inspections, all industry sectors are independent and an operator does not use their sUAS for operations in two sectors (i.e. they exclusively serve one sector).

\section{Representative UAS Selection}

Through a review of the collected type data for the 400+ vehicles, six general categories of sUAS were defined based on size, capabilities, and costs. A representative sUAS was defined from the average characteristics of the systems in the group. The ConOps and business case for the sector was examined to select the appropriate representative sUAS based on the sector needs. Table II displays the six categories of sUAS considered in this 
analysis and displays their key cost parameters. The operating cost presented is an estimate of the average hourly operating cost for the vehicle in an external provider service model considering vehicle fuel costs, maintenance, travel to site, insurance, and pilot wage. Note that the operating cost does not include an amortization of acquisition cost. The acquisition cost represents average costs of the platform, software, and basic sensor packages.

Table II. sUAS general categories and representational vehicle information. This research sought to define generic categories that represent average acquisition and operating costs for sUAS of varying payload and operating capabilities.

\begin{tabular}{|l|l|l|l|}
\hline UAS Category & $\begin{array}{l}\text { Acquisition } \\
\text { Cost }\end{array}$ & $\begin{array}{l}\text { Operating } \\
\text { Cost }\end{array}$ & Example Vehicle \\
\hline$<10$ lb multipurpose multirotor & $\$ 4000$ & $\$ 75$ & 3DR X-8 Octocopter \\
\hline 25 lb to 55 lb multipurpose multirotor & $\$ 20,000$ & $\$ 150$ & Airbornedrones A-2 \\
\hline$<55$ lb agriculture sprayer multirotor & $\$ 15,000$ & $\$ 100$ & HSE AG-V8A Octocopter \\
\hline$>55 \mathrm{lb}$ agriculture sprayer helicopter & $\$ 150,000$ & $\$ 300$ & Yamaha R-MAX \\
\hline$<10 \mathrm{lb}$ fixed wing & $\$ 25,000$ & $\$ 150$ & Precision Hawk Lancaster \\
\hline 25 lb to 55 lb fixed wing & $\$ 50,000$ & $\$ 500$ & Insitu ScanEagle \\
\hline
\end{tabular}

5. Characterizing Market Value through Various Metrics

The final step of the market analysis is to assess the market value of the sector. Numerous metrics exist to measure market value. The goal of this analysis is to provide a holistic impression of the commercial UAS industry. Therefore, a variety of market metrics are defined for each sector that display the economic impact on different constituencies including the UAS manufacturers, service providers, clients (service purchasers), and employees/operators. The seven metrics chosen for this analysis are described below. Each metric provides unique insight, but each also is subject to specific assumptions and uncertainties that must be recognized.

Market Size Metrics - The first two metrics concern the potential revenue opportunity available to sUAS service providers. The external service provider model likely overestimates both metrics while the internal provider model assumption likely leads to an underestimate. Metrics three and four characterize the size of the industry that may be supported by the sector, and their associated capital investment costs, respectively. The serviceable addressable market and UAS capital investment may be considered direct economic impact metrics.

1) Total Addressable Market (TAM) - The TAM represents the potential revenue opportunity for a sUAS service provider if the full market share were to be met by the UAS industry.

2) Serviceable Addressable Market (SAM) - The SAM represents the potential revenue opportunity for a sUAS service provider considering limitations such as market penetration, service scalability, and non-UAS competition, among others.

The SAM and TAM may best be understood through Figure 3. The blue rectangle represents the total sUAS market, across all sectors. The orange circle, or sector TAM, is the total value of operations in a specific sector if the entire sector need could be fulfilled through sUAS services. For example, the orange circle may be thought of in the power line inspection industry as the case where every mile of power line is inspected per regulation by sUAS services. The green circle represents the sector SAM, or the total market value that is actually anticipated to be captured by sUAS services in the year 2020. The green circle is smaller than the orange circle because sUAS will not likely reach $100 \%$ market penetration by 2020 , if ever. There are situations where companies may desire to use traditional techniques or where sUAS are not practical.

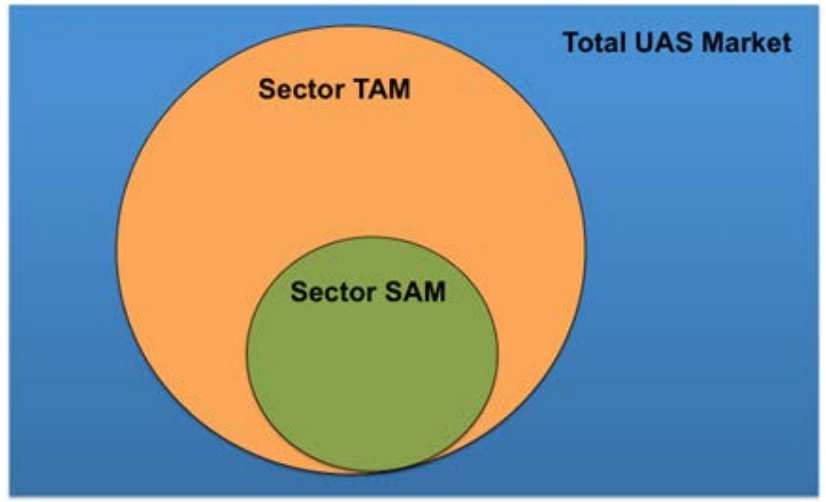

Figure 3. Visual representation of the Serviceable Addressable Market (SAM) and Total Addressable Market (SAM) for a UAS sector. The sector TAM is the entire value of the UAS market that could potentially be captured assuming 100\% market penetration, while the SAM is the subset that is forecast to be captured. 
3) UAS Application Industry Size - For this analysis the size of the sUAS industry for a specific application is presented as the number of single operator service providers needed to meet the market service demands. Each service provider is assumed to provide 250 full days of operation per year. In implementation, it is likely there will be more service providers than predicted in this study as markets do not operate at $100 \%$ efficiency due to factors such as competition, weather, and logistics. As the market matures it is also likely that single operator service providers will coalesce into multi-operator service provider companies; this dynamic is not captured by the current analysis.

4) UAS Capital Investment - The capital investment metric represents the potential sales of sUAS necessary to meet the demands of the service providers. The capital investment of the service providers is assumed to be the cost of their sUAS and basic command and control equipment. Specialized sensor package needs, company overhead, transportation vehicles, advanced ground stations and other likely capital costs that a sUAS service provider may encounter are not included in this initial analysis.

Additional Direct Economic Impact Metrics - These economic impact metrics characterize capital savings directly accrued by a client as a result of UAS adoption.

5) Operations Savings Potential - The operations savings potential metric represents the historical operations costs to complete the mission through conventional methods less the sUAS serviceable addressable market (costs to complete the service with sUAS) for the segment of the market utilizing sUAS services. This metric therefore captures the operations savings a company may realize through use of sUAS services compared to the status quo service.

6) Revenue Recovery Potential - The revenue recovery potential represents client value that may be realized as a result of new or enhanced capabilities provided by the sUAS application. Potential revenue recovery may typically be considered as "production recovery" or as "failure avoidance." Production recovery represents the client value of reduced downtime for inspection or repair. Failure avoidance represents customer value due to the reduction of unplanned repair and damage payments.

External Economic Impact Metric - Potential value realized by entities as a result of the sUAS operations, but not considered as an economic activity.

7) Safety Improvement Potential - This metric seeks to characterize the value of safety improvements resulting from sUAS operation. This metric is typically presented in this research as a discussion of the safety improvements relative to current operations possible through sUAS utilization.

It should be noted that multiple other metrics exist to characterize market size, particularly indirect and induced economic impact metrics. For example, AUVSI included in Ref. 14 multiple forms of indirect impacts and induced impacts that characterize the downstream multiplier effect of money infused into an economy (i.e. "reexpenditures"). This multiplier effect may at times be quite large. This analysis chose not to consider such indirect or induced impacts (except safety improvement) due to the difficulty of estimating these factors and the inflationary effect they have on market prediction by considering impacts outside of the direct UAS industry.

\section{Results}

Sector by sector economic impact market analyses were completed according to the methodology outlined in the previous section. Sensitivity studies within some sectors also provide insight into how study assumptions and UTM operational constraints impact the projected value of specific sUAS sectors. In order to review the potential overall influence of the UTM project on the UAS industry, the individual sectors are compared to one another and aggregate economic impact information is presented. The six direct impact economic metrics enable a detailed comparison among sectors in terms of where value is generated, which stakeholders capture the value generated, and which sectors are more sensitive to certain changes in ConOps or UTM TCL operational constraints.

The discussion presents a variety of figures drawn from the economic impact market analysis. Key takeaways, as well as limitations and assumptions, are discussed for each figure. The goal of presenting the data through this means, rather than providing a simple overall dollar comparison of the sector values, is to promote a holistic understanding of the market landscape in the reader and communicate market trends and study limitations, rather than providing a direct numeric sector ranking. 


\section{A. Full Market Commercial sUAS Economic Impact Findings for 2020}

Figure 4 displays the aggregate direct economic impact metrics for each of the commercial sUAS sectors enabled by UTM TCLs 1 and 2. The "base," or lowest market adoption assumptions were utilized to create Figure 4; therefore the market projections may be thought of as conservative estimations given the assumptions of this analysis. The direct economic impact metrics include the serviceable addressable market (total revenue opportunity captured by sUAS service providers), capital investment (value of sector sUAS), operations savings (expenses saved by converting existing services to sUAS services) and revenue recovery (revenue gained as a result of increased production or reduced failure due to sUAS services).

It is immediately recognizable from Figure 4 that the "cropland precision agriculture" sector is forecasted to be the largest commercial sUAS market by a significant margin. The "construction" and "heavy industry inspection" sectors are the next two largest sectors, but each is a mere fraction of the potential total economic impact of cropland precision agriculture.

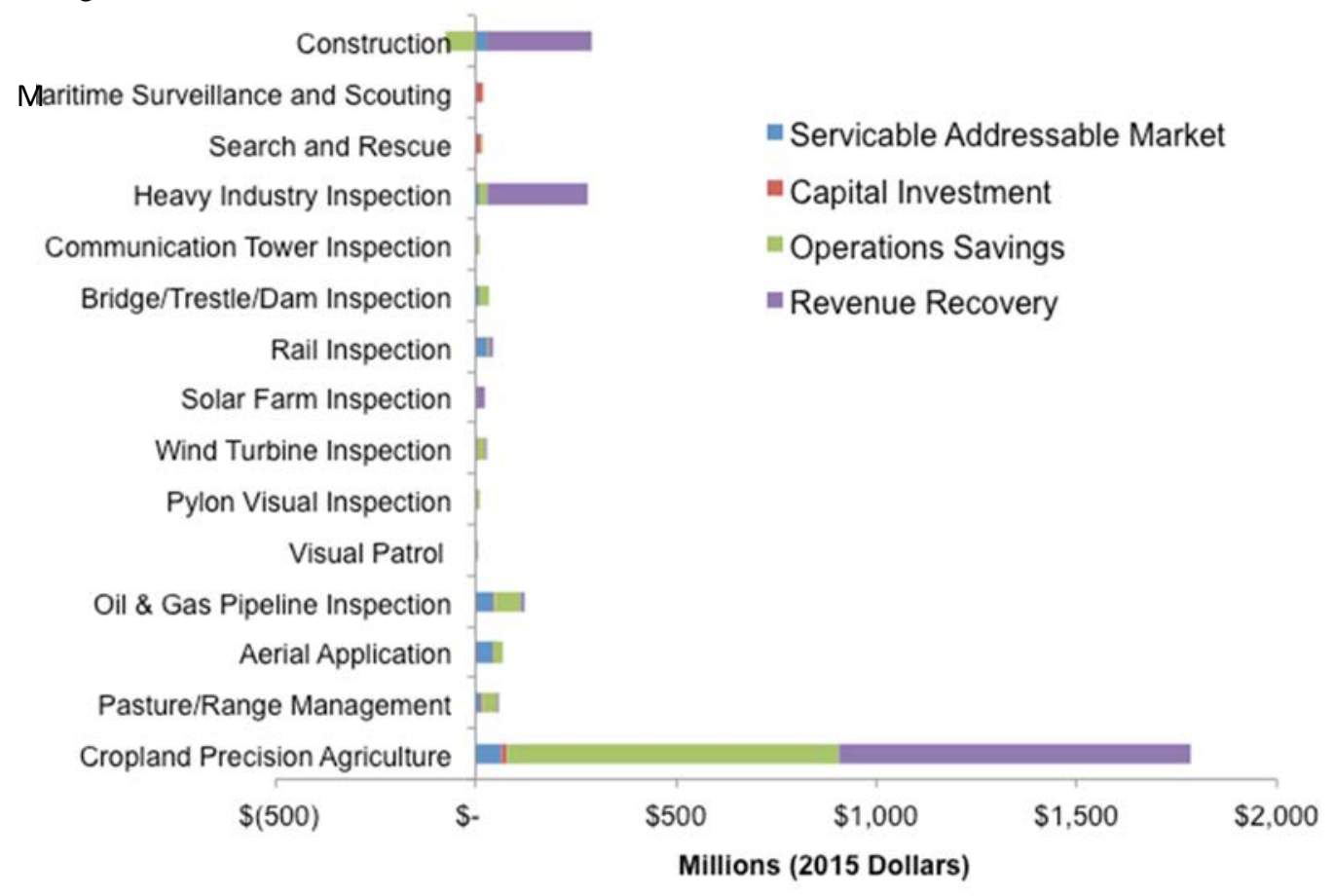

Figure 4. Direct economic impacts of 2020 commercial sUAS market. Industry composite displaying projected direct market impacts of commercial applications enabled by UTM technologies in 2020.

Beyond providing an overall picture of the commercial sUAS industry market projections in 2020, significant structural elements of the industry may be identified in Figure 4. First of all, it is apparent that a significant proportion of the direct economic impact of the three largest sectors is categorized as revenue recovery. This suggests that commercial sUAS services will provide cropland precision agriculture, heavy industry inspection and construction with a means to significantly increase their revenue over what was previously possible. Upon further investigation, the drivers of this revenue recovery are apparent. Unmanned aircraft systems in cropland precision agriculture have been estimated to provide a crop yield increase of up to $7 \% .{ }^{15}$ Resultantly, because the value of US crop production is $\$ 210$ billion dollars annually, a $7 \%$ increase in revenue (even with a rather low adoption rate of roughly $6 \%$ of the market) results in the nearly one billion dollars of annual revenue recovery to the agricultural industry shown in Figure 4; this number grows rapidly with higher predicted market penetration assumptions.

The heavy industry sector experiences similarly large revenue recovery due to the ability of facilities to continue the operation of some mission critical infrastructure during sUAS visual inspection, a feat that was not possible with hazardous manned inspections. Finally, the construction sector predicts sUAS will improve on-time project completion and identify building errors early. This capability, even if only affecting $0.5 \%$ of project revenue for a small percentage of the market, produces significant value in the one trillion dollar industry.

A second takeaway from Figure 4 is that the other significant proportion of the precision agriculture value results from operations savings to the farmers. Industry advocacy groups suggest that precision agriculture by sUAS may reduce chemical use by up to $40 \%{ }^{15}$ The US agricultural chemical and fertilizer industry is a $\$ 30$ billion dollar 
industry. Therefore a moderate reduction in chemical usage even in a small number of farms (low market penetration by 2020) results in significant overall economic impact.

Figure 4 supports the reader to understand a few key takeaways and limitations of the current market analysis. First, cropland precision agriculture in particular may reflect the influence of technology and market optimism. For many years, precision agriculture has been identified by multiple market studies as the leading commercial application for UAS technologies. ${ }^{14}$ As a result, this application has had an unequal share of media coverage and service provider investment. It may therefore be possible that the estimations for sUAS impact, especially the projected increases in crop yield and reduction in chemical use, may be overstated. However, even if both of these parameters are reduced by 50\%, the economic impact of the precision agriculture industry remains nearly as large as all the other sectors combined. Therefore, this analysis supports previous findings by other researchers and firms that precision agriculture represents one of the largest commercial sUAS market for the young industry.

While Figure 4 supported a high level analysis of the economic impact structure of the three largest commercial UAS sectors, it did not provide the resolution to support the same analysis for the remainder of the sectors that exhibit smaller potential economic impacts. Therefore, Figure 5 was developed to display the economic impact composition of each sector based on the four direct impact economic metrics. While the sectors have dramatically different total values, this comparison enables a study of the structural differences between the sectors in terms of where value is derived.

From Figure 5, it may be seen that the different sectors create economic impact through a wide mix of mechanisms. Some sectors, such as "maritime surveillance and scouting" and "search and rescue" create economic value nearly completely through capital investment in UAS and associated technologies. These two sectors are characterized by a large number of operators with a low rate of deployment but a high desired rate of readiness.

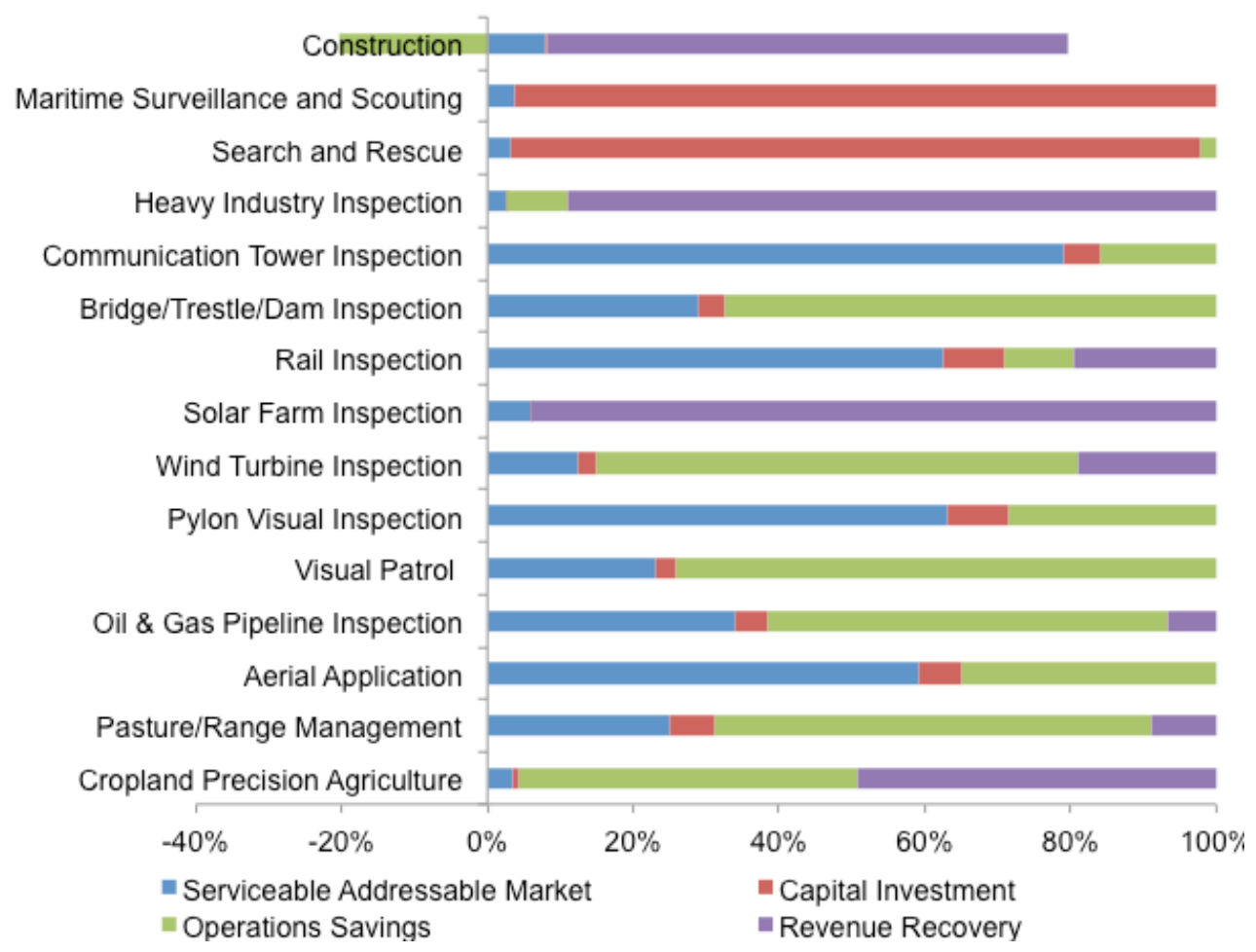

Figure 5. Direct economic impacts structure analysis for 2020 commercial sUAS market. Industry composite displaying the contribution fractions for each of the four direction economic impact metrics to each sector.

Sectors such as "construction," "heavy industry inspection," and "solar array inspection" produce a majority of their economic impact by recovering revenue for the client. Yet another group of sectors, including "rail inspection," "communications tower inspection" and "aerial application," derive a majority of their economic impact from the serviceable addressable market, or the value captured by sUAS service providers.

The differences between the commercial sUAS sectors in terms of where value is created also influences the distribution of stakeholder benefits. For example, those sectors that have a high percentage of their economic impact categorized as capital investment will most significantly benefit the sUAS manufactures, while potentially deterring 
sUAS service providers from entering the market unless there is a large SAM to capture. Sectors with large revenue recovery and operations savings potential will benefit the sUAS clients most significantly.

It should be noted that Figure 5 presents the total economic impact of all the sectors as a normalized value. This may lead to confusion that an industry such as "solar array inspection" has a greater total revenue recovery than cropland precision agriculture, for example. However, Figure 5 is only presenting the composition percentages of the four impact metrics within each industry. Therefore, in this case, "cropland precision agriculture" delivers far more revenue recovery to farmers than "solar array inspection" returns to utility companies because the total market size of the former is much larger than that of the latter.

\section{B. Commercial sUAS Market Impact Findings for UTM TCLs 1 and 2}

The remainder of the discussion shall focus on the serviceable addressable market and capital investment metrics only. While the revenue recovery and operations savings metrics represent a majority of the potential economic impacts of sUAS up to 2020, they represent value delivered to the client and not necessarily value captured within the sUAS industry (by manufactures or operators). Figure 4 and Figure 5 displayed the industries that represent the greatest overall economic impact. The interpretation of these figures may provide insight into UTM TCL operational constraints that will best support these high impact industries. However, the remainder of this analysis will focus on how sUAS ConOps limitations and operational constraints may influence the SAM and capital investment metrics, which act as a proxy for the internal revenue value of the sUAS industry.

Figure 6 displays the relative contributions of all sectors to the total SAM enabled by UTM TCL 1. From the findings of UTM TCL 1, these operations are assumed to be constrained to line of sight flight in geofenced airspace, by a single sUAS, weighing less than $55 \mathrm{lbs}$, without people or significant property underneath. From Figure 6 it is evident that cropland precision agriculture accounts for $50 \%$ of the total market, and agriculture applications in general accounts for $84 \%$ of the total. These percentages indicate that UTM TCL 1 produced technologies and capabilities that enable wide scale sUAS adoption in the agricultural industry and capture much of the potential value therein. Agriculture applications account for a majority of the UTM TCL 1 enabled market as they are not generally constrained by the line of sight or population overflight constraints; however, as will be shown in the sensitivity studies in sub-section C, the $55 \mathrm{lb}$ UAS weight limitation is binding on aerial application. Many of the other sectors are not enabled to operate sUAS to any degree, or to only small degree due to the operational constraints of UTM TCL 1. Please note that the economic impacts presented are in 2015 dollars, calculated with the service provider model market (versus an internal provider market) assumption, and under the base market adoption assumption.

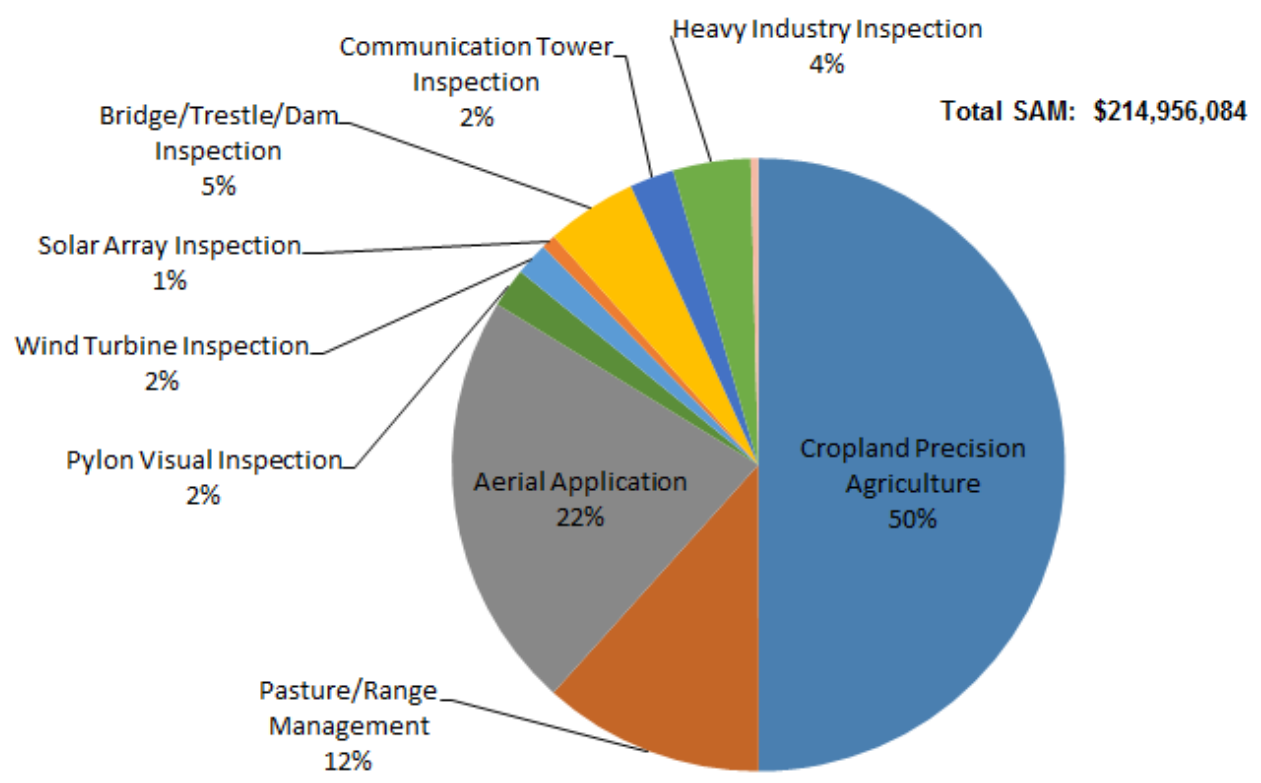

Figure 6. UTM Technology Capability Level 1 enabled sector contributions to 2020 sUAS SAM with base market penetration and independent service provider model assumptions. The base, or lowest projected market penetration estimates were utilized. The independent service provider model assumes sUAS are owned and operated by $3^{\text {rd }}$ party contractors. Only sectors enabled by UTM TCL 1 ConOps and technologies are considered. 
Figure 7 displays the increase in total SAM and the shift in relative sector value contribution when sectors enabled by UTM TCL 2 are included. The beyond visual line of sight capability supported by UTM TCL 2 is key in enabling operations such as railroad inspection and oil \& gas pipeline inspection, each representing significant market wedges. Additionally, the UTM TCL 2 allowance to fly over personnel involved in the sUAS operation enables applications in the construction sector. Although farming applications do not realize significant economic gains between UTM TCLs 1 and 2, they continue to represent over 50\% of the potential market.

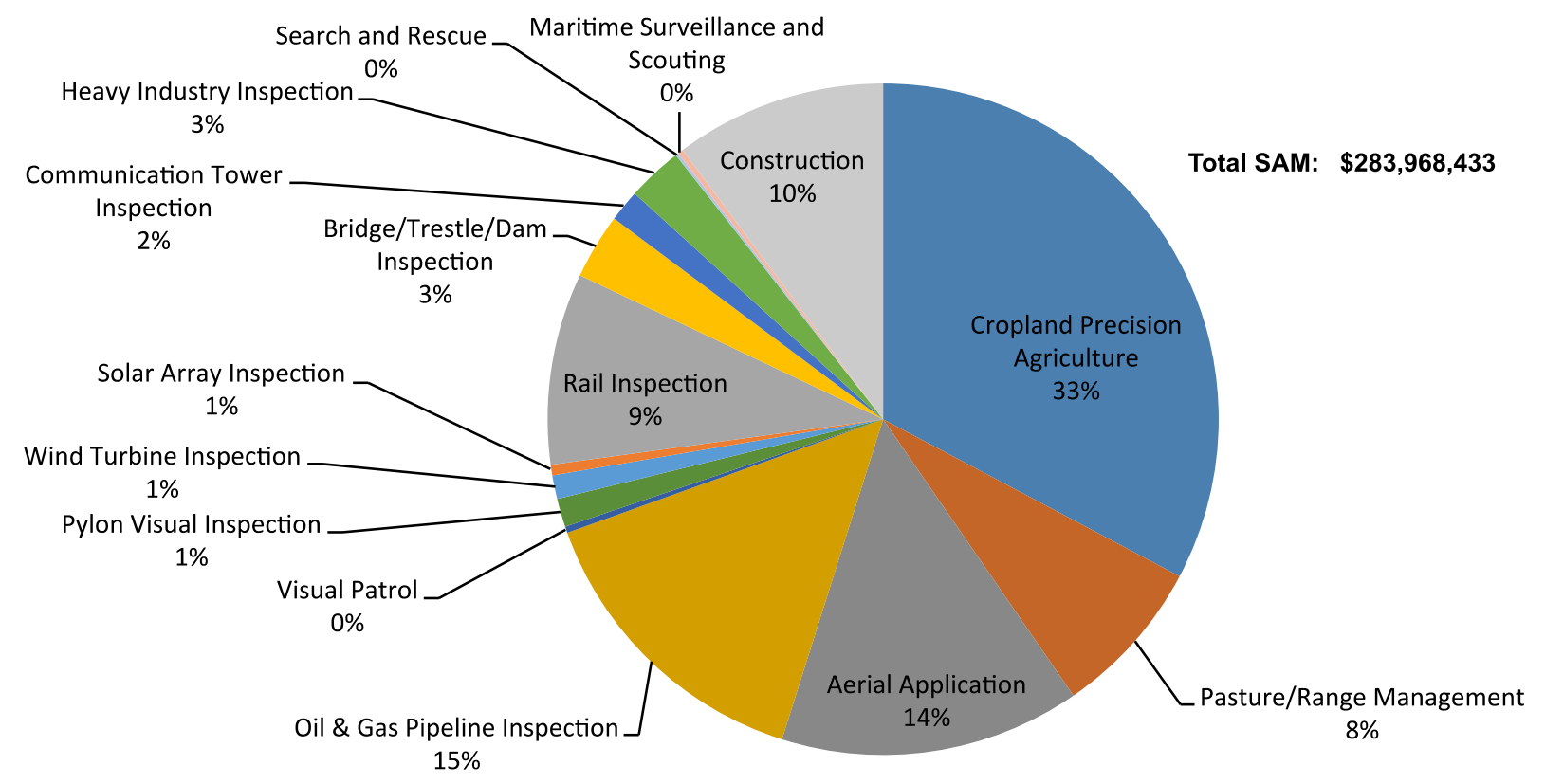

Figure 7. UTM Technology Capability Level 2 enabled sector contributions to 2020 sUAS SAM with base market penetration and independent service provider model assumptions. The base, or lowest projected market penetration estimates were utilized. The independent service provider model assumes sUAS are owned and operated by $3^{\text {rd }}$ party contractors. Only sectors enabled by UTM TCLs 1 or 2 ConOps and technologies are considered.

\section{Commercial sUAS Market Impact Finding Sensitivity Studies}

1. Service Provider Model Sensitivity

As discussed previously, a significant assumption in this study is that an independent service provider model will be used across all industries. This model assumes a client hires an independent sUAS service provider to complete the application. This model is viable for many industries such as solar panel inspection and bridge, trestle, and dam inspection where the utilization for a single client may be low and likely does not warrant the capital costs of the sUAS, training, insurance and other expenses of operation. The model less accurately represents industries such as rail and pipeline inspection where industries currently have a mix of internal and external providers. Finally, the independent service provider model is unreasonable for sectors such as maritime surveillance and security where it would not be economically viable to put a service provider on every seagoing vessel.

In order to explore the sensitivity of the provider model assumption on the projected 2020 commercial sUAS market, an alternative internal service provider model was applied to industries that were likely to conduct sUAS operations without a $3^{\text {rd }}$ party service provider. Figure 8 displays the change in the SAM for the "mixed service provider market" where the three agriculture sectors, rail inspection, dam, trestle and bridge inspection, search and rescue, maritime surveillance and scouting, and construction sectors use the internal service provider model while the other sectors continue to use the independent provider model.

The impact of the mixed service provider market is to generally reduce the SAM of the sectors that adopt the internal service provide model. This occurs because the internal operators do not charge a profit margin in their hourly sUAS operation fee. This means the SAM represents the estimated cost for labor, travel, insurance, energy and other non-revenue costs. The result is to significantly reduce the total commercial sUAS SAM from \$284 million to $\$ 169$ million. Much of this service provider revenue potential loss occurs in the farming sectors. Under the mixed provider model market assumption, oil and gas pipeline inspection emerges as the new leading 
serviceable addressable market for sUAS application enabled by UTM TCLs 1 and 2. Remember, however, that this sector is not possible through UTM TCL 1 alone due to visual line of sight limitation.

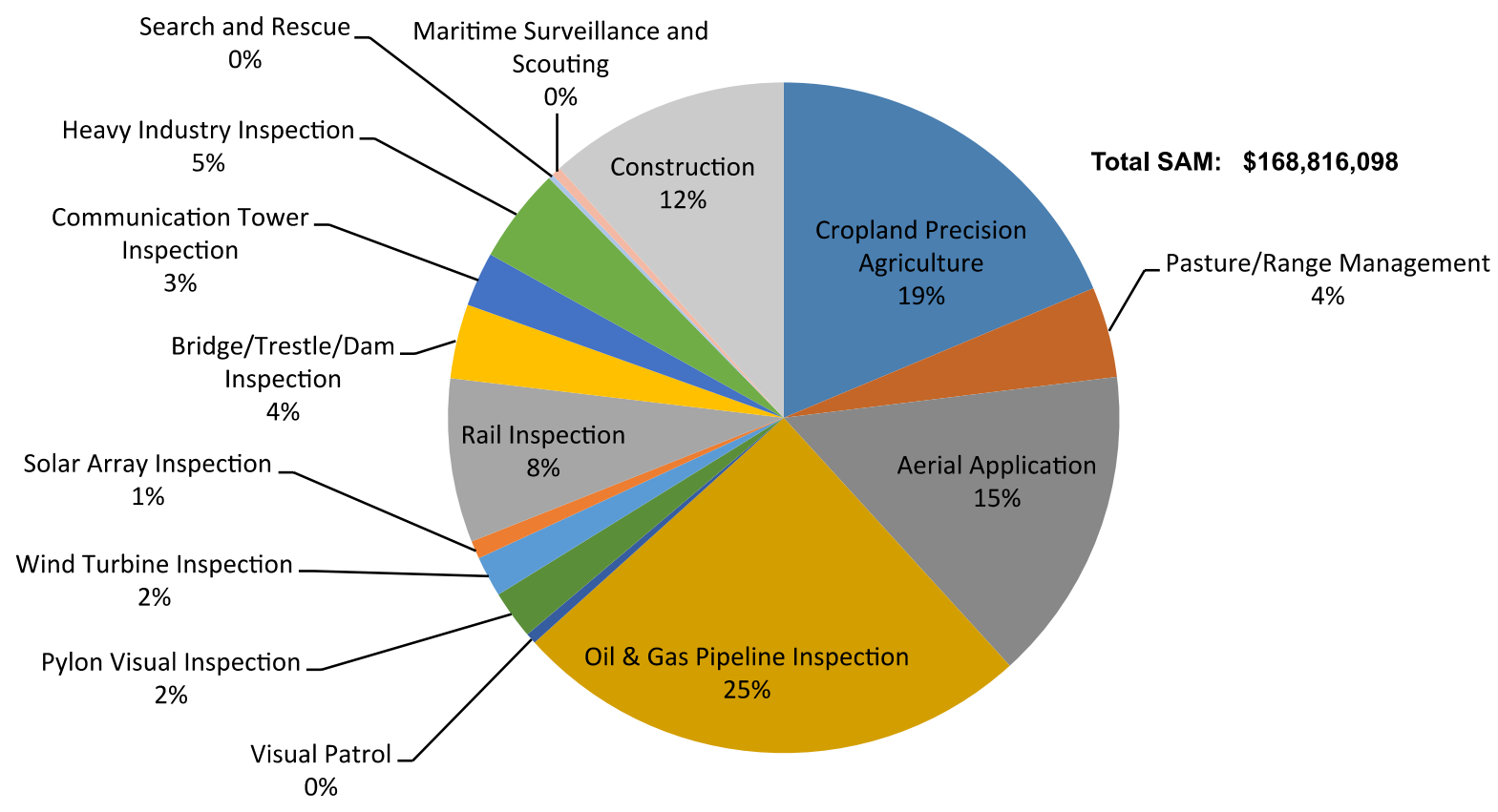

Figure 8. UTM Technology Capability Level 2 enabled sector contributions to 2020 sUAS SAM with base market penetration and mixed service provider market assumptions. The base, or lowest projected market penetration estimates were utilized. The mixed service provider model assumes some sectors contact sUAS services, while other sectors internally provide their own sUAS services. Sectors enabled by UTM TCLs 1 or 2 ConOps and technologies are considered.

While a change of market model from independent to internal service providers lowers the SAM of the farming sectors, it does quite the opposite in terms of capital investment. The independent service provider model simulates a highly efficient sUAS market where vehicles and pilots operate at $100 \%$ capacity across the sector (an overestimate when considering market distribution, logistical and temporal efficiency, competition, etc). The high efficiency assumption results in an underestimation of the capital investment necessary to meet the sector needs.

Therefore, as Figure 9 and Figure 10 displays, the mixed provider market dramatically increases the capital investment in those industries that adopt an internal provider model. The total capital investment of the industry increases from $\$ 89$ million to $\$ 2.8$ billion. Most significantly, the farming sectors expand from accounting for $52 \%$ of the capital investment in the industry to $95 \%$. This is a result of the large number of potential sUAS purchasing farms and their low utilization of the vehicles. A farm may only use a sUAS for 4 to 40 days of operations a year on average (pasture and range management may be much higher) resultantly paying a large cost per usage in order to have the vehicles on hand and readily deployable. It is not an unreasonable market assumption for farms to purchase their own vehicles as farmers may make operations decisions from day to day based on weather conditions, a factor that would make scheduling an independent sUAS service provider difficult.

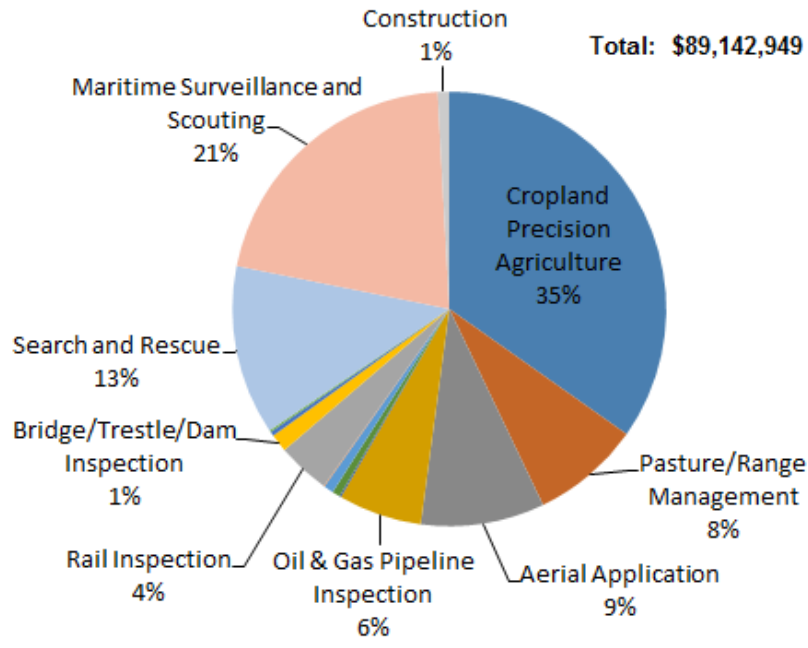

Figure 9. Technology Capability Level 2 enabled sector contributions to total sUAS capital investment with base market penetration and independent service provider model assumptions. 
The discussion above suggests that the commercial sUAS market is highly sensitive to the service provider model that is assumed. In practice, the commercial sUAS market will likely contain sectors exhibiting both types of models, as well as mixed models. The driving factor that determines which model will prevail in a sector is likely to be regulation. While manufacturers and technologists may reduce the costs of advanced sUAS and increase performance so most operators can easily fly the vehicles, the FAA training requirements for pilots may prevent the widespread internal provider model and operational use of these vehicles. The time and expense to certify as a private pilot (currently required to fly a UAS commercially) will dissuade most farmers and other potential operators from purchasing their own systems, thus promoting the independent service provider model.

\section{Market Adoption Rate Sensitivity}

A second significant assumption made through the market analysis concerns the unknown market adoption rate for commercial sUAS in each sector by 2020. Emerging technologies typically follow an "s-curve" adoption rate with initial usage among a small number of early-adopters. This is followed by a rapid period of growth in the mainstream market and concludes with an asymptotic approach to the steady-state adoption level as late-adopters begin to use the product or service. The slope of the s-curve (rate of market adoption) is dependent upon factors unique to the particular technology and industry. ${ }^{16}$

Confounding the situation further for commercial sUAS adoption is regulatory uncertainty. Figure 11 displays the proposed influence of regulatory uncertainty on sUAS market adoption. The blue curve represents what a traditional s-curve market adoption for commercial sUAS may have looked like. However, entities such as AUVSI have proposed that sUAS market adoption has been stunted by regulatory uncertainty and restrictive FAA policies for commercial sUAS operations. The red curve in Figure 11 visualizes the impact of such regulatory uncertainty through a lesser slope and delayed inflection of the technology adoption curve. It is anticipated that upon the establishment of permanent, favorable sUAS policies by the FAA, the industry will rapidly expand as manufactures and operators previously constrained by regulations compete for market segments. ${ }^{14}$

Figure 11 also reveals two potentially interesting impacts of regulation uncertainty on the commercial sUAS industry. First of all, the area between the two curves (designated as region 1) may be interpreted as proportional to the total economic value either lost or delayed due to the influence of uncertain regulations. In an unimpeded market (blue curve), the market would have adopted sUAS technologies more quickly and derived the resulting commercial value from their use. However, in the case of sUAS, uncertain regulations and the temporary measures have stunted the market and delayed the market realization of sUAS potential value.

The second interesting impact of regulatory uncertainly occurs during the late stages of market adoption and is indicative of a "path dependency" of technology adoption (designated as region 2 in Figure 11). As can be seen, two potential paths are represented for the stunted sUAS technology adoption curve: one that exceeds the natural curve adoption asymptote and one that achieves a lower adoption percentage. In actuality, there are an unlimited number

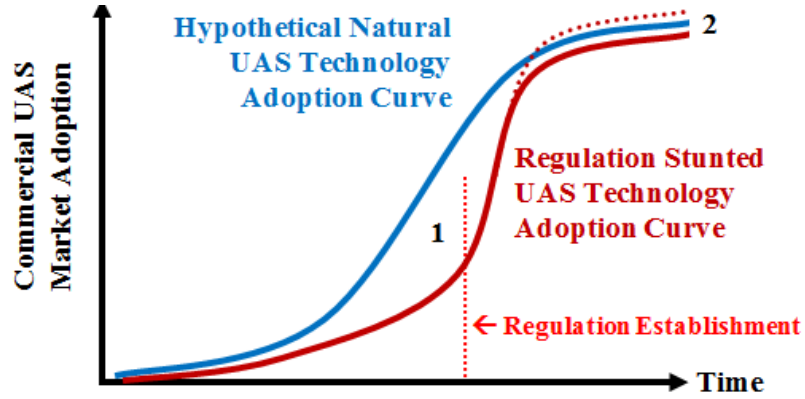

Figure 11. The influence of regulatory uncertainty on sUAS market adoption. The delay of FAA sUAS rulemaking may have slowed market adoption. of potential paths for the regulatory delayed curve resulting in a variety of final adoption states. While regulatory uncertainty may initially delay the adoption of sUAS technologies and stunt the market, this condition does not necessarily hobble the long-term market. If delayed rule-making by the FAA enables more advanced technologies to be developed to ensure safer sUAS operations, then perhaps incidents may be avoided that could have hypothetically crippled the natural market. Alternatively, some industries may find alternative solutions to sUAS while the technology is limited by uncertain regulation meaning these markets could potentially be unrecoverable. The concept of 
path dependency in market adoption is common in economics and the social sciences. This paper does not comment further on what the long-term impact of uncertain regulations in the commercial sUAS market may be, but this should be considered as an area for future efforts.

The influence of regulatory uncertainty increases the uncertainty in the estimate of market adoption rate. Subject matter expertise was primarily used to develop these estimations for this study. Sensitivity studies of market adoption rate were conducted in each sector by calculating the economic impact with a base, medium and high adoption rate. A comparison of the forecasted markets reveals that the market adoption percentage will significantly influence the size of the commercial sUAS industry in 2020. As more accurate forecast models are developed, they should be implemented to refine the assumptions of this analysis. Furthermore, if final FAA regulations are developed before 2020 and lead to a step-change in the market adoption (rapid adoption by a significant portion of industry) the 2020 economic impact may reflect the higher market penetration assumptions of this analysis.

\section{Technology Capability Level ConOps Constraint Sensitivities}

In addition to impacting the overall technology market adoption rate for commercial sUAS as shown above, regulatory constraints and UTM TCL operational constraints may also significantly influence the economic impact of some sectors. The dependence of three sectors on operations constraints for maximum altitude, maximum takeoff weight and population density restrictions for operation over people are presented as examples of how these sensitivity studies may inform the requirements for UTM or policy officials.

The first operation constraint sensitivity study explores the variability in the communications tower inspection sector as a result of the current $500 \mathrm{ft}$ commercial sUAS operation ceiling proposed by the FAA. ${ }^{17}$ Communications tower inspection involves the at-height imaging by UAS of structures ranging from under $100 \mathrm{ft}$ to over $2000 \mathrm{ft}$ in height. Figure 12 suggests that the increase of the sUAS ceiling above $500 \mathrm{ft}$ to at least $2000 \mathrm{ft}$, while keeping the other conditions of UTM TCL 1 constant, increases the total direct economic impact of the sector by roughly $22 \%$. The increase is a result of the additional structures that a sUAS service provider will be able to inspect due to the increase in operating altitude. Furthermore, current communications tower inspections are completed by climbers exposing these individuals to significant risk. Expanding the sUAS inspection services to additional facilities may therefore also provide potentially substantial safety benefits.

The second operating constraint sensitivity study explores the variability in economic impact of the aerial application sector as a result of the sUAS $55 \mathrm{lb}$ maximum takeoff weight operation restriction. ${ }^{3}$ Aerial application involves low altitude flight over croplands and the spraying of chemicals and other substances. Small UAS have been shown as capable of fulfilling the spraying needs of small farms and specialty crop spraying operations..$^{10}$ However, current manned aerial application vehicles can carry thousands of pounds of payload. These missions, which represent the major share of the current aerial application sector, would not be possible under a $55 \mathrm{lb}$ sUAS operating limit.

Figure 13 displays that the relaxation of the maximum takeoff weight restriction for an aerial applicator sUAS up to $300 \mathrm{lbs}$ may result in an increase in economic impact of over $450 \%$ for this sector. The increase is dramatic due to the significantly larger market sUAS will

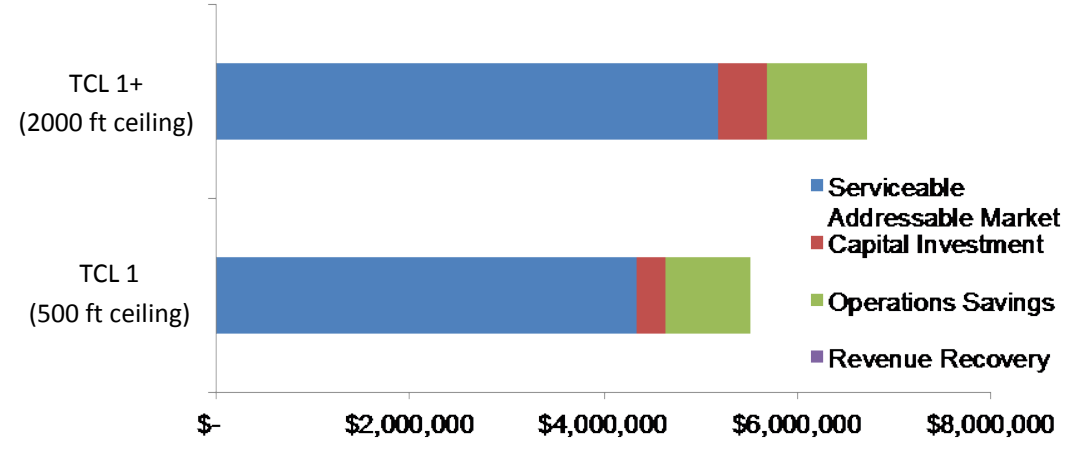

Figure 12. Communications tower inspection operating altitude constraint sensitivity study. A 500ft operational ceiling reduces potential 2020 market value up to $18 \%$.

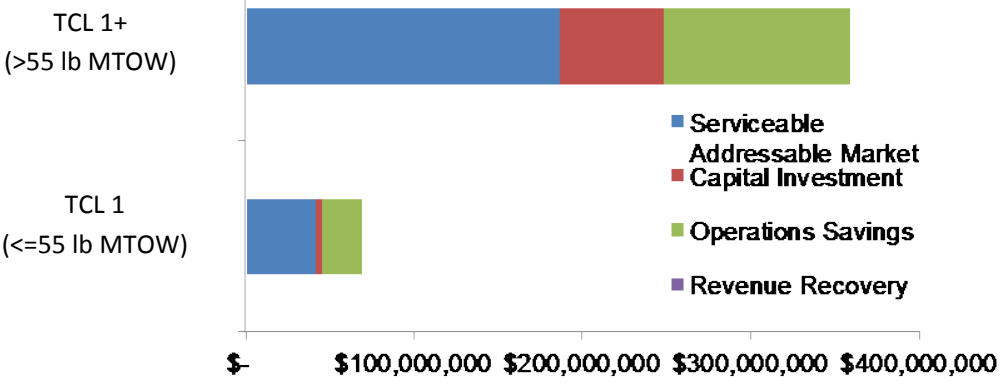

Figure 13. Aerial application maximum takeoff weight constraint sensitivity study. A 55lb maximum takeoff weight reduces potential 2020 market value up to $79 \%$. 


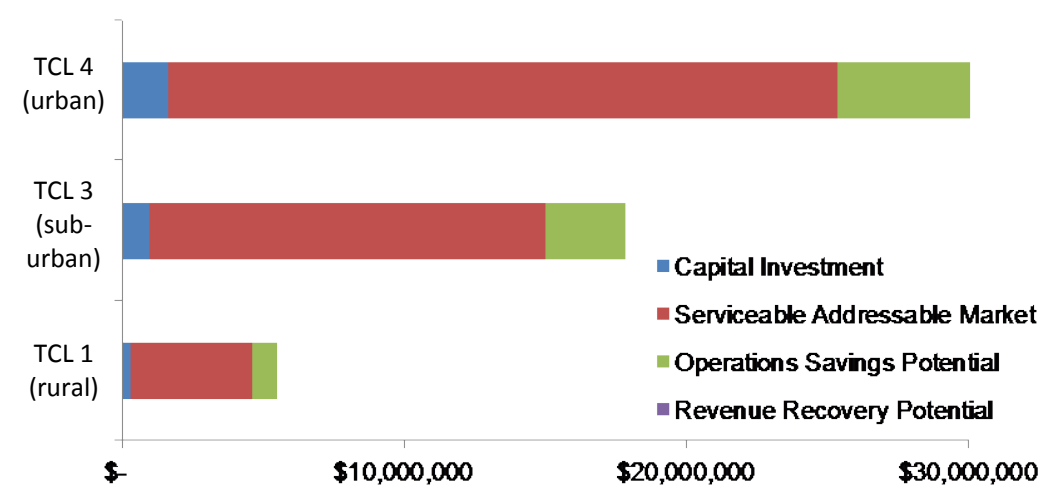

Figure 14. Communications tower inspection population density overflight constraint sensitivity study. Flight over more populated areas is expected to significantly increase potential 2020 market value of communications tower inspection. be able to serve, and the cost savings the vehicles are anticipated to provide compared to current manned aerial operations. There was no economic impact due to revenue recovery from aerial application as the missions are assumed to currently be completed by manned aircraft or ground based systems.

The final operation constraint sensitivity study explores the variability of the economic impact of the communications tower inspection sector as a result of the population density overflight limitations of the UTM TCLs. Technology Capability

Levels 1 and 2 do not support operations over people or significant property. These UTM TCLs will enable communications tower inspections only in remote areas. Technology Capability Level 3 is proposed to enable operations over moderately populated areas such as in a suburban setting. Finally, UTM TCL 4 is proposed to enable operations over densely populated areas such as in an urban setting. Figure 14 indicates a significant dependence of economic impact on the population overflight standard enabled by the UTM TCLs. The sensitivity of economic impact to overflight population density varies from sector to sector depending upon what percent to the missions are located in populated areas, however nearly all sectors have significantly greater market potential with flight over suburban and urban areas.

\section{Conclusion}

The commercial UAS economic impact market analysis presented in this study projects the state of the industry in the year 2020 through the consideration 16 leading market sectors. The 16 sectors were derived from 74 commercial sUAS applications that were predicted to be supported with the findings from the NASA UAS Traffic Management (UTM) project. The analysis determined the economic impact of each sector through the application of seven market metrics. Three market adoption assumptions and two service provider models were also considered to capture uncertainty in the rate of UAS services market penetration and type of service model, respectively. This work is unique in that it adopted a traffic management perspective to assess the potential economic value of new UAS technologies and services with respect to UTM Technology Capability Level (TCL) phased operational constraints.

The market analysis found that sUAS application for precision agriculture created the largest economic impact by a significant degree compared to any other sector. The bulk of the precision agriculture sector value was supported by UTM TCL 1 findings that enable line of sight flight over sparsely populated areas. The development of beyond visual line of sight capabilities in UTM TCL 2 was shown to be a key enabling technology in numerous other business sectors including pipeline and railroad inspection, construction, and maritime applications. Technology Capability Level 2 findings were shown to result in a serviceable addressable market (SAM) expansion of over $30 \%$ for commercial sUAS.

A variety of sensitivity studies were completed to characterize the variability of select UAS sectors' economic value to key UTM operational constraints. A relaxation of the initial $500 \mathrm{ft}$ maximum operating altitude constraint to $2000 \mathrm{ft}$ provided a moderate market expansion for the communications tower inspection industry. While such a ceiling is not reasonable for all airspaces, this study suggests that UTM capabilities to relax the altitude constraint in the vicinity of large communication towers may provide increased economic value and personnel safety.

Furthermore, the proposed maximum takeoff weight constraint of $55 \mathrm{lbs}$ was found to have a significant market impact for the aerial application sector, but have little to no effect in the other sectors. If later UTM TCLs enabled the use of agricultural UAS of weights up to $300 \mathrm{lbs}$, this analysis suggests an up to $450 \%$ market expansion may occur for UAS aerial application. Finally, the UTM TCL population density overflight constraints were found to have a large impact in the market forecast for a majority of the sectors. The support of UAS operations over suburban and urban regions though UTM TCLs 3 and 4 is projected to increase the market impact communications tower inspection sector by up to $600 \%$ compared to UTM TCLs 1 and 2 rural flight area limitations. Similar market expansions are expected in many other UAS sectors. 


\section{Appendix}

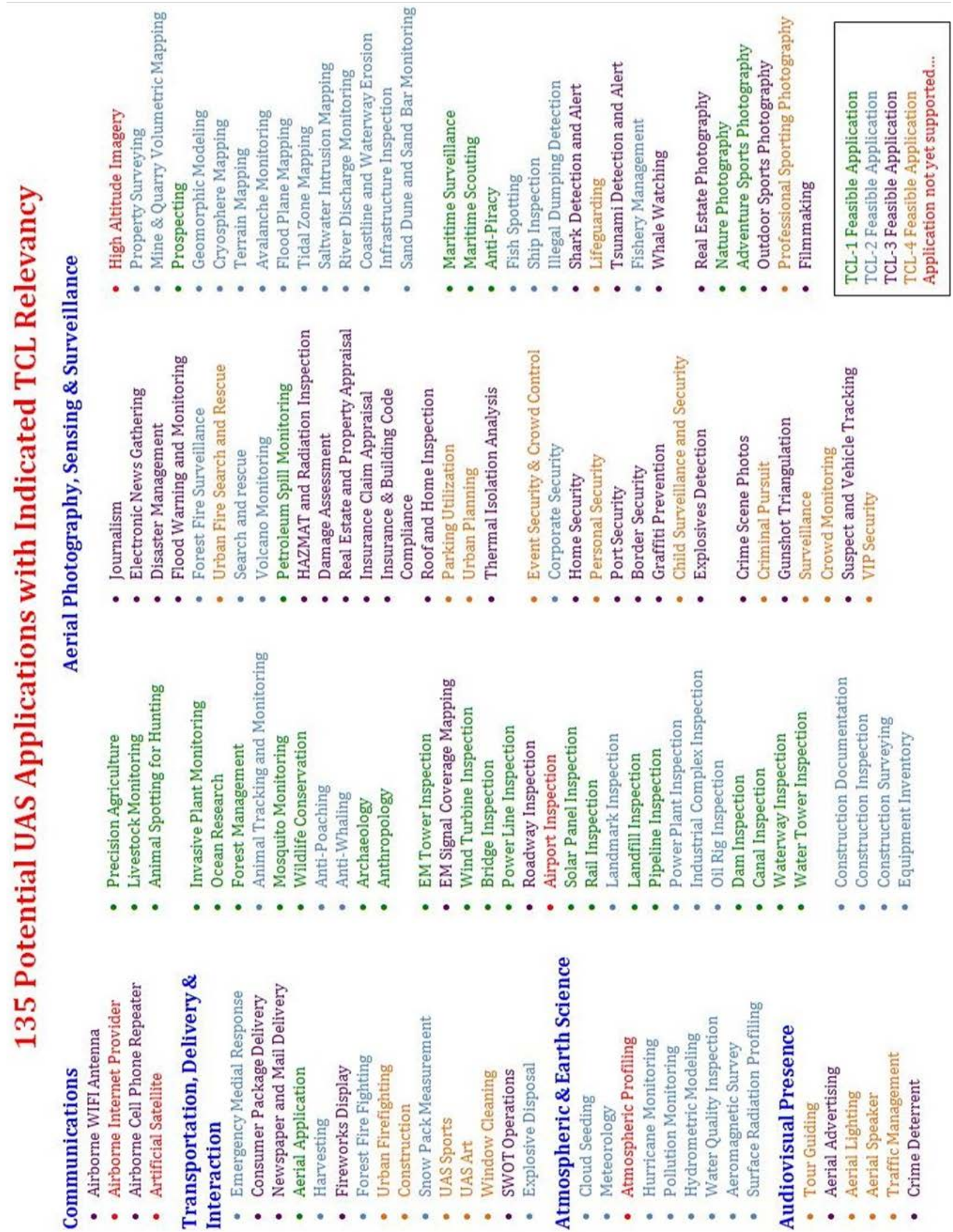




\section{Acknowledgments}

This material is based upon work supported by the National Aeronautics and Space Administration under Grant Number NNX14AT14H issued through the NASA Education Aeronautics Scholarship Program.

\section{References}

${ }^{1}$ Gertler, J. (2012). U.S. Unmanned Aerial Systems. Washington, DC: Congressional Research Service.

${ }^{2}$ Teal Group Corporation. (2015). World Unmanned Aerial Vehicle Systems: 2015 Market Profile and Forecast (12 ${ }^{\text {th }}$ ed.). Fairfax, VA: Teal Group Corporation.

${ }^{3}$ FAA Modernization and Reform Act of 2012. Pub. L. No. 112-95, § 331(6), 126 Stat. 72.

${ }^{4}$ Malone, P., Apgar, H., Stukes, S., \& Sterk, S. (2013). Unmanned Aerial Vehicles Unique Cost Estimating Requirements. IEEE Aerospace Conference. Big Sky, MT: IEEE.

${ }^{5}$ Volpe. (2013). Unmanned Aircraft System (UAS) Service Demand 2015-2035: Literature Review and Projections of Future Usage (Version 0.1). Cambridge, MA: John A. Volpe National Transportation Systems Center.

${ }^{6}$ Skrzypietz, T. (2012). Unmanned Aircraft Systems for Civilian Missions. Potsdam, Germany: Brandenburg Institute for Society and Security.

${ }^{7}$ Federal Aviation Administration. (2015). FAA Aerospace Forecast: Fiscal Years 2015-2035. Washington DC: Department of Transportation.

${ }^{8}$ Quater, P. B., Grimaccia, F., Leva, S., Mussetta, M., \& Aghaei, M. (2014, July). Light Unmanned Aerial Vehicles (UAVs) for Cooperative Inspection of PV Plants. IEEE Journal of Photovoltaics, 4(4), 1107-1113.

${ }^{9}$ Giles, D. K., \& Billing, R. C. (2015). Deployment and Performance of a UAV for Crop Spraying. Chemical Engineering Transactions, 44, 307-312.

${ }^{10}$ Irizarry, J., \& Johnson, E. N. (2014). FHWA-GA-1H-12-38. Feasibility Study to Determine the Economic and Operational Benefits of Utilizing Unmanned Aerial Vehicles (UAVs). Atlanta, GA: Georgia Institute of Technology.

${ }^{11}$ Kimchi, G. et al. (2015). Unmanned Aerial Vehicle Delivery System, US20150120094 A1. Washington, DC: United States Patent and Trademark Office.

${ }^{12}$ National Aeronautics and Space Administration. (2015). Unmanned Aircraft Systems (UAS) Traffic Management (UTM) Fact Sheet. Retrieved April 12, 2016, from http://utm.arc.nasa.gov/docs/utm-factsheet-02-23-16.pdf.

${ }^{13}$ Wargo, C. A., Church, G. C., Glaneueski, J., \& Strout, M. (2014). Unmanned Aircraft Systems (UAS) Research and Future Analysis. IEEE Aerospace Conference. Big Sky, MT: IEEE.

${ }^{14}$ Jenkins, D., \& Vasigh, B. (2013). The Economic Impact of Unmanned Aircraft Systems Integration in the United States. Association for Unmanned Vehicle Systems International.

${ }^{15}$ Lucey, D., Aho, K., Ewing, L., Honeycutt, G. L., \& Rosenberg, Z. (2014, May). Fast Facts on Unmanned Agriculture. Mission Critical, 4(2), 8-9. Retrieved from http://www.auvsi.org/.

${ }^{16}$ Rogers, M. E. (2003). Diffusion of Innovations ( $5^{\text {th }}$ ed.). New York, NY: Simon \& Schuster.

${ }^{17}$ Federal Aviation Administration. (2015). FAA-2015-0150. Operation and Certification of Small Unmanned Aircraft Systems [NPRM]. Washington, DC: Department of Transportation. 